\title{
The critical role of subduction in Earth's halogen distribution
}

\author{
L. RuZiÉ-HAMILTON ${ }^{1 *}$, R. BuRGESS ${ }^{1}$, P.L. Clay ${ }^{1}$, B.
} JOACHIM-MROSKO ${ }^{2}$, D. CHAVRIT ${ }^{3}$, D.R. HILTON ${ }^{4}$, M.R. PERFIT ${ }^{5}$ AND C. J. BALLENTINE ${ }^{6}$

${ }^{1}$ Department of Earth and Environmental Sciences, University of Manchester, Manchester, M13 9PL, UK;

(*correspondance: lorraine.ruzie@manchester.ac.uk)

${ }^{2}$ Institute for Mineralogy and Petrography, University of Innsbruck, Innrain, 52A-6020, Innsbruck, Austria;

${ }^{3}$ Institut de Physique du Globe de Paris, 75005 Paris, France;

${ }^{4}$ Scripps Institution of Oceanography, University of California San Diego, La Jolla, California 92093-0244, USA;

${ }^{5}$ Department of Geological Sciences, University of Florida, Gainesville, Florida 32611, USA;

${ }^{6}$ Department of Earth Sciences, University of Oxford, South Parks Road, Oxford, OX1 3AN, UK.

Halogens are volatile and hydrophilic elements that play a critical role in the ability of the oceans to support life. It is likely that during accretion much of the terrestrial halogen budget was concentrated at the Earth's surface either in hydrous melt or water [1], therefore early oceans may have been significantly more saline than today [2] .

To date, the magnitude of the global halogen fluxes into or out of the Earth's mantle over Earth history remains debated [3] and their role in controlling ocean salinity unknown. Iodine is hugely concentrated in the ocean sediments relative to the other halogens [4] and provides a particularly sensitive tracer to determine halogen subduction efficiency. We investigate halogen behaviour, and iodine in particular, in three different ocean plate boundary settings back arcs, mid ocean ridges and transform faults.

Here we show that $\mathrm{I} / \mathrm{Nb}$ is strongly correlated with $\mathrm{Ba} / \mathrm{Nb}, \mathrm{Th} / \mathrm{Nb}, \mathrm{Pb}$ isotopes and $\mathrm{K} / \mathrm{Ti}$. The data are consistent with the halogen budget in the upper mantle being a mixture between the most depleted upper mantle and a fluid-modified mantle enriched during its residency in subduction zones. We distinguish between different volatile reservoirs during subduction, and determine the effective returning halogen flux into the mantle.

[1] Clay et al. 2017, Nature 551, 614-618; [2] Knauth, L.P. 1998, Nature 395, 554-555 (1998) [3] Barnes et al. 2018, Springer Geochemistry, Chapter 8, 545-590; [4] Deruelle et al. 1992, Earth Planet. Sci. Lett. 108, 217-227. 